\title{
Proposing Effective Framework for Animation Based Learning Environment for Engineering Students
}

\author{
Rajesh Kumar Kaushal ${ }^{1}$, Surya Narayan Panda ${ }^{2}$, Naveen Kumar \\ ${ }^{1,2,3}$ Chitkara University Institute of Engineering \& Technology, Chitkara University, Punjab, India \\ ${ }^{1}$ rajesh.kaushal@chitkara.edu.in, \\ 2snpanda@chitkara.edu.in \\ 3naveen.sharma@chitkara.edu.in
}

\begin{abstract}
Computer animations have been used since a long time to improve comprehension and the learning outcome but the outcomes of the past empirical studies were not uniform. Some studies statistically proved the effectiveness of computer animations but other studies failed to produce evidences in favour of computer animations. There is need of a standard framework that can suggest what should be there in an effective computer animation based learning environment. The present research is proposing a standard framework that suggests under which conditions computer animations are effective, which combination of scaffolding is effective in such environments, does design principles matter while making animations and which design principles are the most effective. A meta-analysis was conducted to find out the effective conditions. An empirical study was conducted to find out effective combination of scaffolding and another empirical study was conducted to find out the effective design principles. The study discovered that computer animations are effective when offered to high prior knowledge students. The study also found that indirect support and adaptive fading is the best combination of scaffolding. Segmentation, cueing/signaling, prediction prompts and modality are proved as the effective design principles.
\end{abstract}

\section{Rajesh Kumar Kaushal}

Department of Computer Applications, Chitkara University Institute of Engineering \& Technology, Punjab rajesh.kaushal@chitkara.edu.in,
Keywords: Computer Animations, Effective Design Principles, Effective Scaffolding, Animation Based Effective Framework

\section{Introduction}

For a long time, researchers have been trying to improve the learning outcome through different teaching methodologies. One such methodology is improving learning outcome through computer animations. The past empirical studies could not find uniform outcomes. Some empirical studies statistically proved the effectiveness of computer animations but the other studies were failed to prove it . The subsequent research revealed that the reason behind such non-uniform results might be due to individual differences. Spatial ability and prior knowledge are considered as the key individual differences. The spatial ability refers to the skill of predicting final output after rotating $2 \mathrm{D}$ or $3 \mathrm{D}$ objects in mind. This ability is required for comprehension while watching complex computer animations . The outcomes of empirical studies associated with individual differences and computer animations were also not uniform.

Some of the studies found that computer animations are effective for high spatial ability students while few other studies found the opposite .

Likewise, few studies proved that computer animations are productive when offered to high prior knowledge learners while few other studies were failed to prove this. 
Even though the results were not uniform but still researchers believe that learning outcome from computer animations are affected by individual differences. The present study thus collected relevant empirical studies and synthesize them through meta-analysis to present a fair estimate of when animations are more effective by comparing two different conditions (animations for high spatial ability students versus low spatial ability students and animations for high prior knowledge students versus low prior knowledge students).

Some of the researchers argued that the reason for such mixed results may be due to ignoring design principles while making animations. The past empirical studies had proved the importance of design principles but neither of them tried to club together the most effective design principles into a single animation as it would offer best of both worlds. The present study addressed and solved this issue through empirical study. The effective design principles are discussed in detail in the section 6 .

Likewise, majority of the researchers presented the idea to consider cognitive load theory while making computer animations. A large number of empirical studies emphasized that scaffolding also positively effects learning outcome in such environments. Scaffolding refers to the way of providing support to learners by an expert in order to complete the task. It constitutes of two elements; support and fading. Withdrawing support in a certain manner to make the learners function independently is known as fading. The literature is still silent about which kind of scaffolding can effectively promote learning as scaffolding can further be categorized. The present paper addressed and solved this issue. In nutshell, there is a need of a standard framework that can set guidelines for an effective computer animation based learning environment.

\section{Objectives}

The primary objective of the present research work is to propose a standard framework for an effective computer animation based learning environment. The proposed framework will answer the following research questions:

1. Under which conditions computer animations leads to better learning environment?

2. Which combination of scaffolding is effective for computer animation based learning environment?

3. Which design principles are effective for computer animations and does they really make a difference?

4. Proposing an effective framework for animation based teaching based on the outcome of the above three research questions.

The outcome of each research question become part of the proposed framework. As a result, it will be a three component framework.

\section{Methodology}

The proposed framework consists of three components. The first component identifies the effective conditions under which computer animations leads to better learning outcome. Two conditions related to individual differences and computer animations were considered during this phase. These two conditions were as follows.

1. Computer animations can improve learning outcome when offered to high spatial ability learners versus low spatial ability learners.

2. Computer animations can improve learning outcome when offered to high prior knowledge

$$
\begin{gathered}
d=\frac{\overline{X_{t}}-\overline{X_{C}}}{S_{\text {pooled }}} \quad \text { Eq. (1) } \\
\text { Hedge's } g=\text { Cohen's } d \times\left(1-\frac{3}{4\left(n_{1}+n_{2}\right)-9}\right) \text { Eq. (2) }
\end{gathered}
$$

learners versus low prior knowledge learners.

A meta-analysis was conducted to find the answer to this research question. A total of 37 experiments (20 related to spatial ability and 17 related to prior knowledge) were analysed from 22 distinct published empirical studies between 1994 to 2016. A total of 18 studies out of these 22 were either indexed in SSCI or SCOPUS database. The databases like Google Scholar, Science Direct and CiteSeer was used to search the articles. The descriptors like "classification of individual differences", "individual differences and animations", "spatial ability and computer animations", "prior knowledge and computer animations", "experts, novices and animations" etc. were used to search the relevant studies. 
The Cohen's d (see Eq.1) and Hedges g (see Eq.2) equations were used to calculate the effect sizes of all the studies related to spatial ability as well as related to prior knowledge. Only those studies were included where population was divided into high and low spatial ability students and learning outcome was measured after teaching through animated and non-animated environments. The same is true for prior knowledge studies.

Thereafter, the weighted mean effect size of low and high spatial ability studies was calculated and compared. Likewise, the weighted mean effect size of high and low prior knowledge studies was calculated and compared. The outcome of the metaanalysis became the first component of the proposed framework.

The second component identifies that which combination of scaffolding is effective for animated environments. An experimental study was conducted to find the answer to this research question. The study was conducted twice to cross verify the results. The first study was conducted at Chitkara University, Punjab State, India and the second study was conducted at Chitkara University, Himachal State, India. The first study was conducted on BCA (Bachelor of Computer Applications) first year students (with age group between 19-20) and the second study was conducted on CSE (Computer Science Engineering) second year students (with age group between 20-21). The post test was used to measure the learning outcome. Thereafter, one-way ANOVA and Tukey HSD PostHoc test were applied to identify which group outperformed in each of the study.

According to literature there are two essential elements of scaffolding i.e. the element of support and the element of fading. The element of fading suggests that the support should be withdraw at some point for independent functioning. The present study argued that the element of support can be further classified as direct and indirect support. Likewise, the element of fading can be further classified as gradual and adaptive fading. Thus, the experimental study made four distinct combinations of scaffolding to find out which one is effective while learning from animated environment. The outcome of this phase became the second component of the framework.

The third component of the framework suggests effective design principles. The empirical studies between 1997 to 2018 were reviewed to find out the effective design principles. The literature was searched on popular databases like Science Direct, Google Scholar and CiteSeer using the keywords like "animations and design principles"," effective computer animations", "dynamic visualization and design elements" etc. Only those research papers were reviewed where the effectiveness of design principles were measured through statistical analysis and dependent variable was either retention score, comprehension score, learning outcome or fixation time.

The study was conducted on CSE second year students (with age group of 20-21) of Chitkara University, Himachal State, on the concept of tree data structures and its operations like insertion and deletion. A total of 50 students participated in the study. All the students were not aware of the concept of tree data structures as it was not part of their curriculum.

Thereafter, the present study conducted an experimental study where the population $(\mathrm{N}=50)$ was randomly divided into two equal groups. The group 1 was taught through the framework having third component as design principles and the group 2 was taught through the framework which did not use design principles as a third component.

Thus, the first framework used computer animations which were designed according to the design principles whereas the second framework used traditional animations designed without design principles. Thereafter, post test results were analysed using a t test to find out which framework improved the learning outcome. This way the present study suggests does design principles really matter and which one?

\section{Effective Conditions to Offer Computer Animations}

The first objective was to find out effective conditions to offer computer animations. The past empirical studies uniformly agree that learning outcome in computer animated environment is influenced by individual differences. The learner's prior knowledge and spatial ability are the two primary individual differences. The spatial ability is associated with the ability to generate, maintain and manipulate objects. These objects may be animated models of concepts. When learners are exposed to 
animate concepts mentally for comprehension then learning outcomes is subjected to spatial ability. The prior knowledge is associated with the learner's prior knowledge of the domain area. Thus, the study considers two essential conditions.

1. Does computer animations are effective for high prior knowledge students or for low prior knowledge students?

2. Does computer animations are effective for high spatial ability students or for low spatial ability students?

The outcome of the meta-analysis become the first component of the proposed framework. The results indicated that spatial ability is not a crucial factor as both high and low spatial ability students profited with computer animations. The weighted mean effect size of high spatial and low spatial ability students was 0.34 and 0.58 respectively. Likewise, the weighted mean effect size of high and low prior knowledge students was 0.49 and -0.16 respectively. A positive weighted mean effect size indicates that treatment has positive impact on the learning outcome. The results also indicate that prior knowledge is a crucial factor as only high prior knowledge students benefitted with the computer animations. The weighted mean effect size of low prior knowledge students was negative. It indicates that computer animated environment is not beneficial for novices. Due to these results the study consider prior knowledge as a crucial factor and consider it as a first component of the proposed framework.

The studies included in meta-analysis are depicted in the Table 1 and Table 2 . The majority of the past studies were observational and very few studies conducted the experiments and presented statistical data. As a result, the present study could only collect 22 different studies (12 for spatial ability and 10 for prior knowledge) which are sufficient enough to estimate the effect because as a thumb rule minimum 10 studies are required to conduct a meta-analysis .

\section{Identification of Effective Combination of Scaffolding}

An expert teacher or instructor is required in computer animated environment to plan strategies and to guide students in effective manner to improve the learning outcome. This procedure is known as scaffolding. The support and fading are the two essential components of scaffolding. The support component refers to expert advise to learner's in order to accomplish the task effectively and the fading component refers to withdrawing support at some point to promote independent functioning of students. This is also known as transferring responsibility back to students.

Table 1 : Studies Included in Meta-Analysis - Spatial Ability

\begin{tabular}{|c|c|c|c|}
\hline S. No. & Author/Year & Domain of Study & $\begin{array}{l}\text { No. of Expt. } \\
\text { Included }\end{array}$ \\
\hline 1 & (Ollerenshaw et al., 1997) & $\begin{array}{l}\text { Concept on Mechanical } \\
\text { Engineering }\end{array}$ & 2 \\
\hline 2 & (Chanlin, 1999) & Concept on Biotechnology & 2 \\
\hline 3 & (Kalyuga, Chandler, \& Sweller, 2000) & $\begin{array}{l}\text { Concept on Mechanical } \\
\text { Engineering }\end{array}$ & 1 \\
\hline 4 & (ChanLin, 2001) & Concept on Physics & 2 \\
\hline 5 & (Schnotz \& Rasch, 2005) & Concept on Basic Science & 2 \\
\hline 6 & (Kalyuga, 2008) & Mathematical Concepts & 1 \\
\hline 7 & (S. I. Park et al., 2009) & Concept on Basic Science & 1 \\
\hline 8 & $\begin{array}{l}\text { (Khacharem, Zoudji, Kalyuga, et al., } \\
\text { 2013) }\end{array}$ & Sports & 1 \\
\hline 9 & (Khacharem, Zoudji, \& Ripoll, 2013) & Sports & 2 \\
\hline
\end{tabular}




\begin{tabular}{|c|c|c|c|}
\hline 10 & (Malone \& Brünken, 2013) & Driving Skills & 1 \\
\hline 11 & $\begin{array}{l}\text { (Khacharem, Zoudji, Spanjers, \& } \\
\text { Kalyuga, 2014) }\end{array}$ & Sports & 1 \\
\hline 12 & (Johnson, Ozogul, \& Reisslein, 2015) & Concept on Electronics & 1 \\
\hline
\end{tabular}

Table 2 : Studies Included in Meta-Analysis - Prior Knowledge

\begin{tabular}{clll}
\hline S. No. Author/Year & Domain of Study & $\begin{array}{c}\text { No. of Expt. } \\
\text { Included }\end{array}$ \\
\hline 1 & (Mayer \& Sims, 1994) & Concept on Mechanical Engineering \& Medical & 4 \\
2 & (Hays, 1996) & Chemistry Concepts & 4 \\
3 & $\begin{array}{l}\text { (Plass, Chun, Mayer, \& Leutner, } \\
\text { 2003) }\end{array}$ & Learning German language & 1 \\
4 & (Boucheix \& Schneider, 2009) & Concept on Mechanical Engineering & 3 \\
5 & (Höffler, Prechtl, \& Nerdel, & Photosynthesis Concepts on Chemistry & 2 \\
& 2010) & & \\
6 & (Khooshabeh \& Hegarty, 2010) & Medical Concepts & 1 \\
7 & (D. Y. Lee \& Shin, 2011) & Concepts on Mechanical Engineering & 1 \\
8 & (Fong, 2013) & Electrolysis Concepts - Chemistry & 2 \\
9 & (E. A. -L. Lee \& Wong, 2014) & Concepts on Biology & 1 \\
10 & (Hui -Yu, 2016) & Medical Domain & 1 \\
\hline
\end{tabular}

The authors of this research paper argued that the element of support can further be classified as direct and indirect support. Likewise, the element of fading can be classified as adaptive fading and gradual fading.

The direct support points to helping students directly by sharing the exact procedure step by step to solve the problem whenever they ask for support. The indirect support points to helping students by means of suggestions, hints or clues. The adaptive fading points to increasing or decreasing support according to the learner's performance. The gradual fading points to decreasing support in decreasing order e.g. initially the learners will get full support from the instructor and then the instructor will withdraw some support gradually and at some point he will fully withdraw the support. It means under gradual fading the instructor will only decrease support gradually and there is no chance to increase it again.

Due to these classifications the study made four distinct combinations of scaffolding by keeping the fact in mind that each combination must have one component of support and one component of fading.
These distinct combinations are listed below.

1. Direct Support Adaptive Fading - DSAF (group 1)

2. Indirect Support Gradual Fading - ISGF (group 2)

3. Direct Support Gradual Fading - DSGF (group 3)

4. Indirect Support Adaptive Fading-ISAF (group 4)

The study was conducted on the concept of "infix to postfix expression conversion using stack". A prior knowledge test was conducted during both the studies and found that all the participants were not aware of the data structures concepts which suggested that all the participants were equal in knowledge. This also ensured unbiased experimental design. Thus, an introductory lecture was delivered to make them aware of basic terminologies like what is infix expression? what is postfix expression and why we need to convert infix to postfix? The authors did not share the procedure to convert infix to postfix expression. The participants were randomly divided into four groups of twenty students each. Each group got different combination of scaffolding treatment. 
The post test was used to measure the learning outcome. Thereafter, one-way ANOVA and Tukey HSD Post-Hoc test were applied to identify which group outperformed in each of the study. The Shapiro-Wilk test was applied on the post test results of both the studies to check the normality of the data and in both the studies the data was found normality distributed. The descriptive analysis of post test scores of study 1 and study 2 are depicted in the Table 3 and Table 4.

Table 3:Descriptive Analysis Post-Test Scores - Study 1

\begin{tabular}{lcccccc}
\hline & $\mathrm{N}$ & Mean & $\begin{array}{c}\text { Std. } \\
\text { Deviation }\end{array}$ & $\begin{array}{c}\text { Std. } \\
\text { Error }\end{array}$ & \multicolumn{2}{c}{$\begin{array}{c}\text { 95\% Confidence } \\
\text { Interval for Mean }\end{array}$} \\
\cline { 5 - 7 } & & & & & $\begin{array}{c}\text { Lower } \\
\text { Bound }\end{array}$ & $\begin{array}{c}\text { Upper } \\
\text { Bound }\end{array}$ \\
\hline DSAF & 20 & 3.15 & 1.531 & .342 & 2.43 & 3.87 \\
ISGF & 20 & 3.15 & 1.663 & .372 & 2.37 & 3.93 \\
DSGF & 20 & 2.60 & 1.429 & .320 & 1.93 & 3.27 \\
ISAF & 20 & 4.45 & 1.191 & .266 & 3.89 & 5.01 \\
Total & 80 & 3.34 & 1.591 & .178 & 2.98 & 3.69 \\
\hline
\end{tabular}

The one-way ANOVA test results of the first study indicated that there was a significant effect of different scaffold combinations on the learning outcome, $\mathrm{F}(3,76)=5.762, \mathrm{p}=.001$.

Likewise, the one-way ANOVA test results of the second study also indicated that there was a significant effect of different scaffold combinations on learning outcome, $\mathrm{F}(3,76)=4.258, \mathrm{p}=.008$. Thereafter, Tukey HSD post-hoc test was applied. Table 5 and Table 6 depicts the post-hoc test results of the first and the second study respectively.

Table 4 : Descriptive Analysis Post-Test Scores-Study 2

\begin{tabular}{lcccccc}
\hline & & & & & \multicolumn{3}{c}{$\begin{array}{c}95 \% \text { Confidence } \\
\text { Interval for } \\
\text { Mean }\end{array}$} \\
\cline { 6 - 8 } Group & $\mathrm{N}$ & Mean & $\begin{array}{c}\text { Std. } \\
\text { Deviation }\end{array}$ & $\begin{array}{c}\text { Std. } \\
\text { Error }\end{array}$ & $\begin{array}{c}\text { Lower } \\
\text { Bound }\end{array}$ & $\begin{array}{c}\text { Upper } \\
\text { Bound }\end{array}$ \\
\hline DSAF & 20 & 3.10 & 1.373 & .307 & 2.46 & 3.74 \\
ISGF & 20 & 3.05 & 2.012 & .450 & 2.11 & 3.99 \\
DSGF & 20 & 3.15 & 1.599 & .357 & 2.40 & 3.90 \\
ISAF & 20 & 4.55 & 1.191 & .266 & 3.99 & 5.11 \\
Total & 80 & 3.46 & 1.668 & .187 & 3.09 & 3.83 \\
\hline
\end{tabular}

The Tukey HSD test depicted in the Table 5 showed that the mean score for the ISAF ( $M=4.45$, $\mathrm{SD}=1.191)$ was considerably different than DSAF $(\mathrm{M}=3.15, \mathrm{SD}=1.53)$, ISGF $(\mathrm{M}=3.15, \mathrm{SD}=1.66)$ and $\operatorname{DSGF}(\mathrm{M}=2.60, \mathrm{SD}=1.42)$.

Table 5: Tukey HSD Post-Hoc Comparisons - Study 1

\begin{tabular}{cccccccc}
\hline & & & & & \multicolumn{2}{c}{$\begin{array}{c}\text { 95\% Confidence } \\
\text { Interval }\end{array}$} \\
\cline { 6 - 8 }$(\mathrm{I})$ group & & $\begin{array}{c}\text { Mean } \\
\text { Difference }\end{array}$ & Std. & & Lower & Upper \\
\hline DSAF & ISGF & .000 & .463 & 1.000 & -1.22 & 1.22 \\
& DSGF & .550 & .463 & .636 & -.67 & 1.77 \\
& ISAF & $-1.300^{*}$ & .463 & .031 & -2.52 & -.08 \\
\hline \multirow{2}{*}{ ISGF } & DSAF & .000 & .463 & 1.000 & -1.22 & 1.22 \\
& DSGF & .550 & .463 & .636 & -.67 & 1.77 \\
& ISAF & $-1.300^{*}$ & .463 & .031 & -2.52 & -.08 \\
\hline DSGF & DSAF & -.550 & .463 & .636 & -1.77 & .67 \\
& ISGF & -.550 & .463 & .636 & -1.77 & .67 \\
& ISAF & $-1.850^{*}$ & .463 & .001 & -3.07 & -.63 \\
\hline \multirow{2}{*}{ ISAF } & DSAF & $1.300^{*}$ & .463 & .031 & .08 & 2.52 \\
& ISGF & $1.300^{*}$ & .463 & .031 & .08 & 2.52 \\
& DSGF & $1.850^{*}$ & .463 & .001 & .63 & 3.07 \\
\hline
\end{tabular}

A mean score points to a learning outcome score of every group which is calculated by adding learning outcome score of every single participant of a group and then dividing it by total number of participants in a group.

Likewise, the Tukey HSD test depicted in the Table 6 showed that the mean score for the ISAF $(\mathrm{M}=4.55, \mathrm{SD}=1.19)$ was convincingly different than DSAF $(\mathrm{M}=3.1, \mathrm{SD}=1.37)$, ISGF $(\mathrm{M}=3.05, \mathrm{SD}=2.01)$ and DSGF $(\mathrm{M}=3.15, \mathrm{SD}=1.59)$. These results matched with the study 1 .

Table 6: Tukey HSD Post-Hoc Comparisons - Study 2

\begin{tabular}{|c|c|c|c|c|c|c|}
\hline \multirow[b]{2}{*}{ (I) group } & \multirow[b]{2}{*}{$(\mathrm{J})$ group } & \multirow{2}{*}{$\begin{array}{c}\text { Mean } \\
\text { Difference } \\
(\mathrm{I}-\mathrm{J})\end{array}$} & \multirow[b]{2}{*}{$\begin{array}{l}\text { Std. } \\
\text { Error }\end{array}$} & \multirow[b]{2}{*}{ Sig. } & \multicolumn{2}{|c|}{$\begin{array}{c}95 \% \text { Confidence } \\
\text { Interval } \\
\end{array}$} \\
\hline & & & & & $\begin{array}{l}\text { Lower } \\
\text { Bound }\end{array}$ & $\begin{array}{l}\text { Upper } \\
\text { Bound }\end{array}$ \\
\hline \multirow[t]{3}{*}{ DSAF } & ISGF & .050 & .498 & 1.000 & -1.26 & 1.36 \\
\hline & DSGF & -.050 & .498 & 1.000 & -1.36 & 1.26 \\
\hline & ISAF & $-1.450^{*}$ & .498 & .024 & -2.76 & -.14 \\
\hline \multirow[t]{3}{*}{$\overline{\mathrm{ISGF}}$} & $\overline{\text { DSAF }}$ & -.050 & .498 & 1.000 & -1.36 & 1.26 \\
\hline & DSGF & -.100 & .498 & .997 & -1.41 & 1.21 \\
\hline & ISAF & $-1.500^{*}$ & .498 & .018 & -2.81 & -.19 \\
\hline \multirow[t]{3}{*}{$\overline{\mathrm{DSGF}}$} & DSAF & .050 & .498 & 1.000 & -1.26 & 1.36 \\
\hline & ISGF & .100 & .498 & .997 & -1.21 & 1.41 \\
\hline & ISAF & $-1.400^{*}$ & .498 & .031 & -2.71 & -.09 \\
\hline \multirow[t]{3}{*}{$\overline{\mathrm{ISAF}}$} & $\overline{\text { DSAF }}$ & 1.450 & .498 & .024 & .14 & 2.76 \\
\hline & ISGF & $1.500^{*}$ & .498 & .018 & .19 & 2.81 \\
\hline & DSGF & $1.400^{*}$ & .498 & .031 & .09 & 2.71 \\
\hline
\end{tabular}


The results of both the studies suggest that the indirect support and adaptive fading was the most effective scaffold combination to enhance the learning outcome. This group outperformed in both the studies. The indirect support might have encouraged the subjects to shift to deep thinking as they were getting support only in the form of hints, clues, and suggestions. The element of deep thinking positively reflected in their post-test scores. Moreover, the adaptive fading made their life easier as they could take help anytime and support could be increased and decreased accordingly. The direct support prevents students to shift towards deep thinking. The study considers these outcomes as the second essential component of the proposed framework.

\section{Identification of Effective Design Principles \& Proposing Framework}

The third component was to find out effective design principles in order to make effective computer animations. An extensive literature review was conducted to find the answer to the research question. The literature between 1997 to 2018 was reviewed to find out the effective design guidelines for computer animations as it was vital to support the third component of the framework. The literature review revealed that segmentation, signaling/cueing, modality and prediction prompts are the most effective design principles.

The segmentation supports the idea that the concept needs to be sub-divided into sub-concepts wherever possible and a separate animation should be made for each sub-concept. The signaling element suggests that it is really beneficial to direct user attention to the most important area of computer animation at any time to make the learners comprehend the underlying process. It is usually done through highlighting key areas with dotted lines and through blinking arrows. There are evidences that signaling improves learning outcome and reduces cognitive load.

The principle of modality suggests that offering animation with voice is an effective combination than offering animation with written text. There is a strong evidence in favour of animations and narrations (auditory explanations of the concepts). The prediction prompt element presents the view that learners should not watch animations passively. The prediction prompts are basically questions that appear as part of the animation (Lin et al., 2016; McElhaney et al., 2015) and ask the user to predict the output and then pauses for some time for the sake of active participation.

A large number of empirical studies in the past had proved the effectiveness of segmentation principle (Ali \& Madar, 2010; Boucheix \& Guignard, 2005; Fong, 2013; Hasler, Kersten, \& Sweller, 2007; Mayer

\& Chandler, 2001; Mayer, Dow, \& Mayer, 2003; Moreno, 2007; Spanjers et al., 2011). These studies are sufficient to support the argument that segmentation in computer animations can lead to better learning outcome. Schneider, Beege, Nebel, \& Rey, 2018 conducted a meta-analysis to find the effect of signaling on retention, transfer of knowledge and cognitive load. The study reported that 117 effect sizes out of 139 were in favor of signaling and retention, 55 out of 70 were in favour of signaling and transfer of knowledge and 19 out of 27 claimed that signaling is useful in reducing the cognitive load (see Table 7).

Table 7 : Effect of signalling on retention, transfer and cognitive load

\begin{tabular}{lccl}
\hline $\begin{array}{l}\text { Dependent } \\
\text { Variable }\end{array}$ & $\begin{array}{c}\text { Total } \\
\text { Comparisons }\end{array}$ & $\begin{array}{l}\text { Effect } \\
\text { Size }\end{array}$ & $\begin{array}{l}\text { Confidence } \\
\text { Interval, 95\% }\end{array}$ \\
Retention & 139 & 0.53 & $0.42-0.64$ \\
Transfer Knowledge & 70 & 0.33 & $0.22-0.43$ \\
Cognitive Load & 27 & 0.25 & $0.04-0.45$ \\
\hline
\end{tabular}

Source: Schneider, Beege, Nebel, \& Rey, 2018

Similarly, Xie, Wang, Zhou, \& Wu, 2016 reported in their meta-analysis that signaling is effective to enhance retention, transfer of knowledge and fixation time (see Table 8).

The fixation time points to total amount of time for which a participant looks at a signaling area. Likewise, De Koning, Tabbers, Rikers, \& Paas, 2009 collected empirical studies (Boucheix \& Guignard, 2005; De Koning, Tabbers, Rikers, \& Paas, 2007;

Table 8 : Effect of signalling on retention, transfer and fixation time

\begin{tabular}{lcc}
\hline Dependent & Effect Size & $\begin{array}{c}\text { Confidence-Interval } \\
\text { Variable }\end{array}$ \\
Retention & 0.53 & $0.36-0.69$ \\
Transfer of Knowledge & 0.36 & $0.23-0.49$ \\
Fixation Time & 0.50 & $0.30-0.71$ \\
\hline
\end{tabular}

Source: Xie et al., 2016 
Fischer, Lowe, \& Schwan, 2008; Fischer, 2008; Lowe \& Boucheix, 2007; Mautone \& Mayer, 2001; Steinke, Huk, \& Floto, 2003)that had reported the effectiveness of signaling approach.

A treatment is said very effective if its effect size is $>0.5$. A larger number of past empirical studies had showed such effectiveness of modality on the learning outcome where the effect size was $>0.5$ (Craig, Gholson, \& Driscoll, 2002; Jeung, Chandler, \& Sweller, 1997; Kalyuga, Chandler, \& Sweller, 1999, 2001; Mayer et al., 2003; Mayer \& Moreno, 1998; Moreno, Mayer, Spires, \& Lester, 2001; Moreno \& Mayer, 1999, 2002; O'Neil et al., 2000)Likewise, numerous empirical studies had proved the effectiveness of prediction prompts while learning from computer animations. (De Koning et al., 2011; Hegarty et al., 2003; Lin et al., 2016; Mayer et al., 2003; McEldoon, Durkin, \& RittleJohnson, 2013; McElhaney et al., 2015; Moreno, 2009; Rittle-Johnson, 2006)

The extensive literature review points out that segmentation, cueing/signaling, modality and prediction prompts are the key design principles. The present study thus considers them as essential component of the proposed framework. After finding the answers to all the research questions the study proposed the framework depicted in the Fig.1.

The present study not only proposed the framework but also evaluated it through well designed empirical study.

The first component of framework suggests that computer animations are only beneficial for the high prior knowledge students. Thus, a 40 minutes' introductory lecture was delivered to all 50 participants ( 2 groups and 25 participants each). The introductory lecture was delivered on what is tree? How it looks like? What are the application areas of tree data structure and Why there is need to learn its operations? The exact procedure of insertion and deletion operations on tree data structure were not shared with them. The study only makes them aware of the prerequisites of tree data structure to improve their prior knowledge. This is the way to follow the first component of the proposed framework.

The second component of the proposed framework suggests that indirect support and adaptive fading (ISAF) is the best way of instructional support while

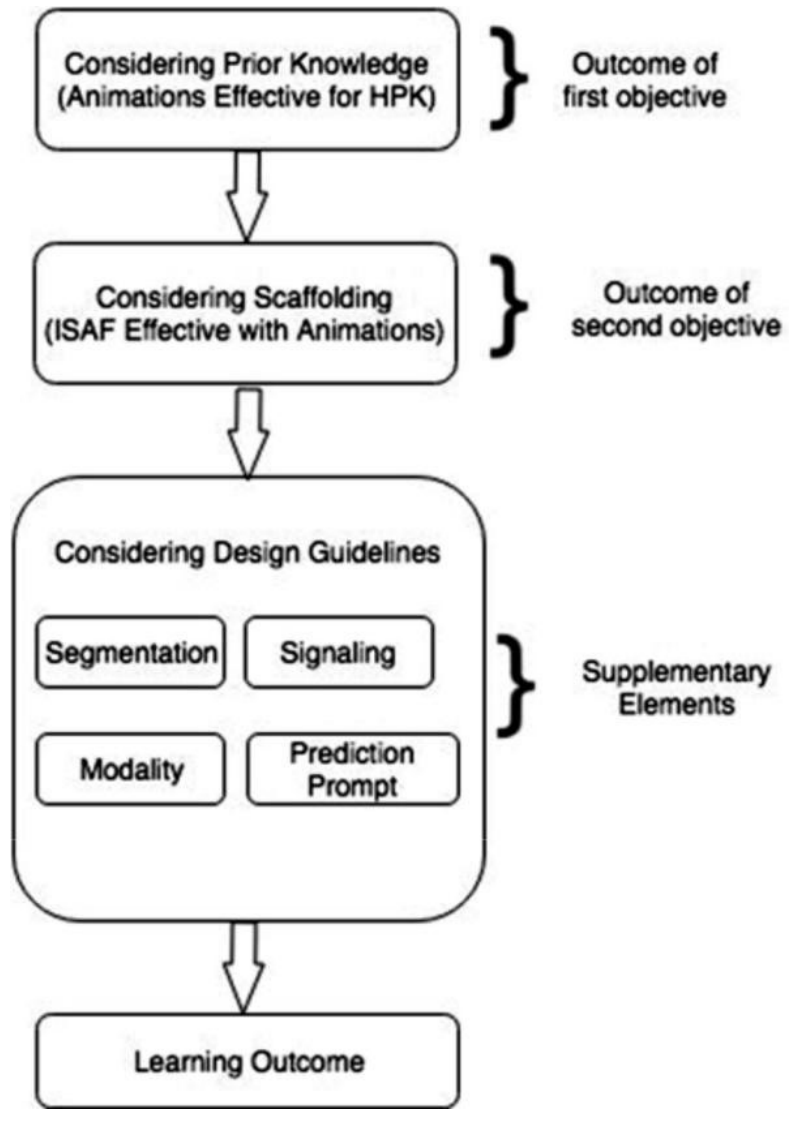

Fig.1 : Proposed framework with three components

learning from computer animation based teaching environment. Thus the instructors followed the same approach and they never helped the students directly by sharing all the steps to solve a specific problem. In fact, hints, clues and suggestions were used as a supporting element during the problem solving phase. Likewise, adaptive fading was used to fade the support. Adaptive fading supports the idea that support should be increased and decreased according to the performance of the students with the condition that the support should be indirect. This is the way to follow the second component of the proposed framework.

The third component of the framework suggests that computer animations must be designed with principles like segmentation, cueing, modality and prediction prompts. The present study designed some computer animations in ADOBE FLASH by following all four design principles on the concept of tree data structures. To find out do design principles really matter, the participants $(\mathrm{N}=50)$ were randomly assigned into two groups of 25 students each. The first group was taught through the framework depicted in 
the Fig. 1. The second group was taught through the framework depicted in the Fig. 2.

Both the frameworks differ only in the last component. The framework depicted in the Fig. 1 followed the design principles whereas the framework depicted in the Fig. 2 follow the traditional animations without any design principles. The learning outcomes of both the groups were measured using independent $t$ test to find out do design principles really matter? The $\mathrm{t}$ test indicated that the difference between both the groups were significant, $t=7.542, p=0.73$. The group 1 who were taught through the framework with design principles performed better $(\mathrm{M}=7.88, \mathrm{SD}=1.12)$ than group2 $(\mathrm{M}=5.44, \mathrm{SD}=1.15)$ who were taught with traditional animations.

The study also computed the impact of the proposed framework by computing effect size using eta square (see Eq. 3.). The eta square equation utilizes $t$ test value and sample sizes to calculate the magnitude. The computed eta squared was 0.542 , which was closed to the large effect size which indicates that framework with design principles is more effective.

\section{Conclusion \& Discussion}

The present study proposed a three component framework where each component is established after rigorous statistical analysis. The first component of the proposed framework clearly suggests that computer animations are effective when offered to high prior knowledge students. A meta-analysis was conducted to establish the first component.

he meta-analysis included the empirical studies from a wide range of subject disciplines due to the fact that computer animations are widely used in almost every domain like chemistry, computer science, physics, biology etc. In future, the same research can be pursued in a specific domain only but it will likely to produce the same results.

The second component of the proposed framework suggests that indirect support and adaptive fading is the best combination while learning from computer animations. The present study did not find out what factors motivates the participants to outperform while learning from indirect support and adaptive fading. It is assumed that indirect support enforces them to a state of deep thinking which makes them fully comprehend the underlying topic. Likewise, it is

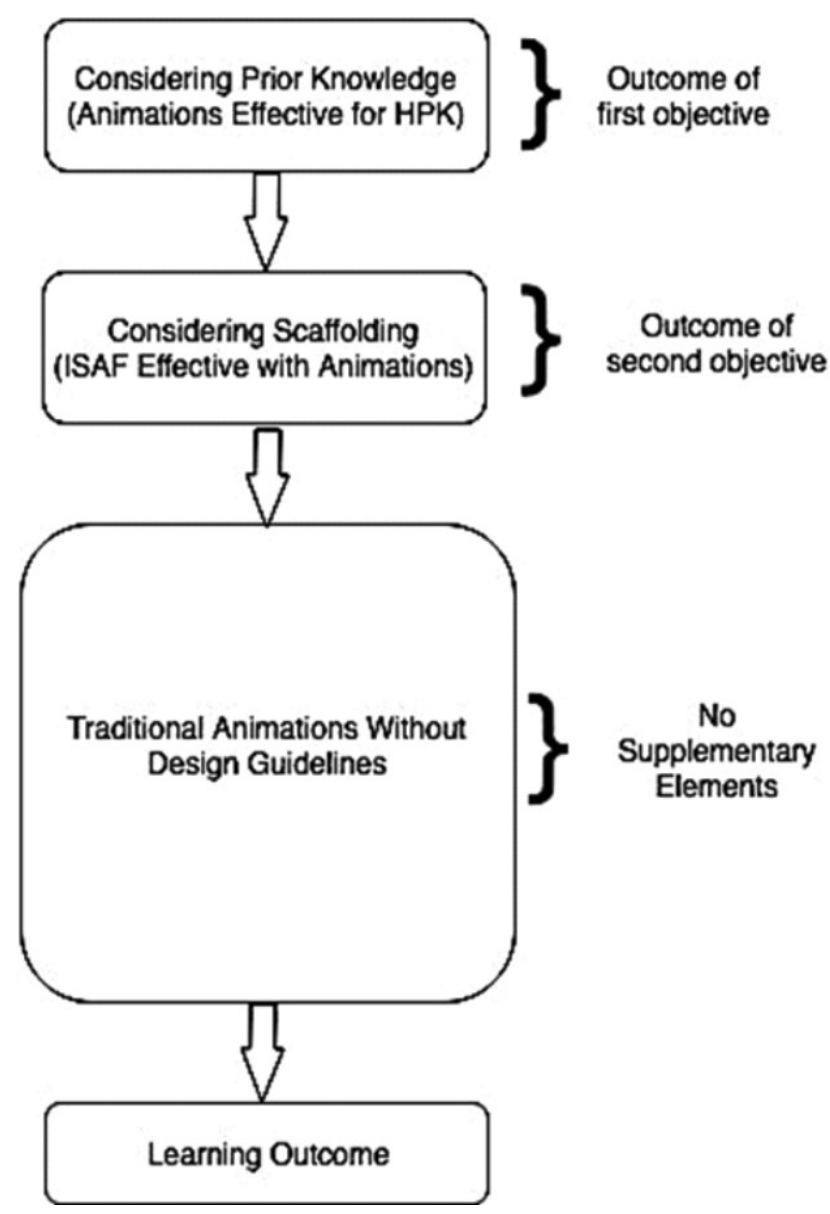

Fig.2 : Proposed framework without design guidelines

$$
\text { Eta Squared }=\frac{t^{2}}{t^{2}+(N 1+N 2-2)} \quad \text { Eq. (3) }
$$

assumed that adaptive fading gives them the flexibility to ask any number of problems and anytime which somehow compensate the restriction of getting help indirectly and thus makes them perform better.

The third component points to effective design principles. The study reported that there is a need to consider design elements while learning with computer animations. The segmentation, modality and signaling helped in reducing the extraneous cognitive load on the students and thus improved their understanding and comprehension score. The prediction prompts increase the germane cognitive load which is also beneficial for the in-depth understanding of the concept being taught. The study suggests that in future there is still need to work more on the design features of computer animations as possibilities for improvement in this domain are still open. 
The most challenging part is integrating all design principles (signalling, segmentation, modality and prediction prompts) into a single animation. It needs in-depth knowledge of animation tools and huge efforts which is sometimes not feasible for a teacher. Thus, more sophisticated tools are required which can make teachers life easy.

The present study also reports that the impact of the proposed framework with design elements is large. The proposed framework can help educators to establish effective learning environment which in turn surely help the learners in comprehension and learning outcome.

\section{References}

[1] Ali, A. Z. M., \& Madar, A. R. (2010). Effects of segmentation of instructional animation in facilitating learning. Journal of Technical Education and Training, 2(2).

[2] Azevedo, R., Cromley, J. G., Winters, F. I., Moos, D. C., \& Greene, J. A. (2005). Adaptive human scaffolding facilitates adolescents' selfregulated learning with hypermedia . Instructional Science, 33(5-6), 381-412.

[3] Barzilai, S., \& Blau, I. (2014). Scaffolding game-based learning: Impact on learning achievements, perceived learning, and game experiences. Computers \& Education, 70, 6579.

[4] Belland, B. R., Walker, A. E., Olsen, M. W., \& Leary, H. (2015). A pilot meta-analysis of computer-based scaffolding in STEM education. Journal of Educational Technology \& Society, 18(1), 183.

[6] Berney, S., \& Bétrancourt, M. (2016). Does animation enhance learning? A meta-analysis. Computers \& Education, 101, 150-167.

[7] Boucheix, J.-M., \& Guignard, H. (2005). What animated illustrations conditions can improve technical document comprehension in young students? Format, signaling and control of the presentation. European Journal of Psychology of Education, 20(4), 369-388.

[8] Boucheix, J.-M., \& Schneider, E. (2009). Static and animated presentations in learning dynamic mechanical systems. Learning and Instruction, 19(2), 112-127.

[9] Byrne, M. D., Catrambone, R., \& Stasko, J. T. (1999). Evaluating animations as student aids in learning computer algorithms. Computers \& Education, 33(4), 253-278.

[10] ChanLin, L. (2001). Formats and prior knowledge on learning in a computer-based lesson. Journal of Computer Assisted Learning, 17(4), 409-419.

[11] Chanlin, L.-J. (1999). Visual treatment for different prior knowledge. International Journal of Instructional Media, 26(2), 213.

[12] Cornoldi, C., \& Vecchi, T. (2004). Visuospatial working memory and individual differences. Psychology Press.

[13] Craig, S. D., Gholson, B., \& Driscoll, D. M. (2002). Animated pedagogical agents in multimedia educational environments: Effects of agent properties, picture features and redundancy. Journal of Educational Psychology, 94(2), 428.

[14] De Koning, B. B., Tabbers, H. K., Rikers, R. M. J. P., \& Paas, F. (2007). Attention cueing as a means to enhance learning from an animation. Applied Cognitive Psychology: The Official Journal of the Society for Applied Research in Memory and Cognition, 21(6), 731-746.

[15] De Koning, B. B., Tabbers, H. K., Rikers, R. M. J. P., \& Paas, F. (2011). Improved effectiveness of cueing by self-explanations when learning from a complex animation. Applied Cognitive Psychology, 25(2), 183-194.

[16] de Pol, J., Volman, M., \& Beishuizen, J. (2010). Scaffolding in teacher--student interaction: A decade of research. Educational Psychology Review, 22(3), 271-296.

[17] Devolder, A., van Braak, J., \& Tondeur, J. (2012). Supporting self-regulated learning in computer-based learning environments: systematic review of effects of scaffolding in the domain of science education. Journal of Computer Assisted Learning, 28(6), 557-573. 
[18] Fischer, S. (2008). Temporal Manipulations in Instructional Animation Design: Is Attention Guiding Thought? Logos Verlag.

[19] Fischer, S., Lowe, R. K., \& Schwan, S. (2008). Effects of presentation speed of a dynamic visualization on the understanding of a mechanical system. Applied Cognitive Psychology: The Official Journal of the Society for Applied Research in Memory and Cognition, 22(8), 1126-1141.

[20] Fong, S. F. (2013). Effects of segmented animated graphics among students of different spatial ability levels: A cognitive load perspective. TOJET: The Turkish Online Journal of Educational Technology, 12(2).

[21] Garg, A., Norman, G. R., Spero, L., \& Maheshwari, P. (1999). Do virtual computer models hinder anatomy learning? Academic Medicine.

[22] Garg, A. X., Norman, G., \& Sperotable, L. (2001). How medical students learn spatial anatomy. The Lancet, 357(9253), 363-364.

[23] Geyskens, I., Krishnan, R., Steenkamp, J.-B. E. M., \& Cunha, P. V. (2009). A review and evaluation of meta-analysis practices in management research. Journal of Management, 35(2), 393-419.

[24] Hasler, B. S., Kersten, B., \& Sweller, J. (2007). Learner control, cognitive load and instructional animation. Applied Cognitive Psychology: The Official Journal of the Society for Applied Research in Memory and Cognition, 21(6), 713-729.

[25] Hays, T. A. (1996). Spatial abilities and the effects of computer animation on short-term and long-term comprehension. Journal of Educational Computing Research, 14(2), 139155.

[26] Hegarty, M. (2004). Dynamic visualizations and learning: Getting to the difficult questions. Learning and Instruction, 14(3), 343-351.

[27] Hegarty, M., \& Kozhevnikov, M. (1999). Types of visual--spatial representations and mathematical problem solving. Journal of Educational Psychology, 91(4), 684.
[28] Hegarty, M., Kriz, S., \& Cate, C. (2003). The roles of mental animations and external animations in understanding mechanical systems. Cognition and Instruction, 21(4), 209-249.

[29] Hegarty, M., \& Waller, D. (2005). Individual differences in spatial abilities. The Cambridge Handbook of Visuospatial Thinking, 121-169.

[30] Höffler, T. N., \& Leutner, D. (2007). Instructional animation versus static pictures: A meta-analysis. Learning and Instruction, 17(6), 722-738.

[31] Höffler, T. N., Prechtl, H., \& Nerdel, C. (2010). The influence of visual cognitive style when learning from instructional animations and static pictures. Learning and Individual Differences, 20(5), 479-483.

[32] Hui-Yu, Y. (2016). The effects of attention cueing on visualizers' multimedia learning. Journal of Educational Technology \& Society, 19(1), 249.

[33] Huk, T. (2006). Who benefits from learning with 3D models? The case of spatial ability. Journal of Computer Assisted Learning, 22(6), 392-404.

[34] Isaak, M. I., \& Just, M. A. (1995). Constraints on the processing of rolling motion: The curtate cycloid illusion. Journal of Experimental Psyc hology: Human P er ce ption a nd Performance, 21(6), 1391.

[35] Jeung, H.-J., Chandler, P., \& Sweller, J. (1997). The role of visual indicators in dual sensory mode instruction. Educational Psychology, 17(3), 329-345.

[36] Johnson, A. M., Ozogul, G., \& Reisslein, M. (2015). Supporting multimedia learning with visual signalling and animated pedagogical agent: Moderating effects of prior knowledge. Journal of Computer Assisted Learning, 31(2), 97-115.

[37] Kalyuga, S. (2008). Relative effectiveness of animated and static diagrams: An effect of learner prior knowledge. Computers in Human Behavior, 24(3), 852-861. 
[38] Kalyuga, S., Chandler, P., \& Sweller, J. (1999). Managing split-attention and redundancy in multimedia instruction. Applied Cognitive Psychology: The Official Journal of the Society for Applied Research in Memory and Cognition, 13(4), 351-371.

[39] Kalyuga, S., Chandler, P., \& Sweller, J. (2000). Incorporating learner experience into the design of multimedia instruction. Journal of Educational Psychology, 92(1), 126.

[40] Kalyuga, S., Chandler, P., \& Sweller, J. (2001). Learner experience and efficiency of instruc tional guidance. Educ ationa 1 Psychology, 21(1), 5-23.

[41] Khacharem, A., Zoudji, B., Kalyuga, S., \& Ripoll, H. (2013). Developing tactical skills through the use of static and dynamic soccer visualizations: An expert -- nonexpert differences investigation. Journal of Applied Sport Psychology, 25(3), 326-340.

[42] Khacharem, A., Zoudji, B., \& Ripoll, H. (2013). Effect of presentation format and expertise on attacking-drill memorization in soccer. Journal of Applied Sport Psychology, 25(2), 234-248.

[43] Khacharem, A., Zoudji, B., Spanjers, I. A. E., \& Kalyuga, S. (2014). Improving learning from animated soccer scenes: Evidence for the expertise reversal effect. Computers in Human Behavior, 35, 339-349.

[44] Khooshabeh, P., \& Hegarty, M. (2010). Inferring cross-sections: When internal visualizations are more important than properties of external visualizations. Human-Computer Interaction, 25(2), 119-147.

[45] Kopper, K. E., McKenzie, D., \& Peterson, D. L. (2009). The evaluation of meta-analysis techniques for quantifying prescribed fire effects on fuel loadings. Res. Pap. PNW-RP582. Portland, OR: US Department of Agriculture, Forest Service, Pacific Northwest Research Station. 24 P., 582.

[46] Lajoie, S. P., Guerrera, C., Munsie, S. D., \& Lavigne, N. C. (2001). Constructing knowledge in the context of BioWorld. Instructional Science, 29(2), 155-186.
[47] Large, A., Beheshti, J., Breuleux, A., \& Renaud, A. (1996). Effect of animation in enhancing descriptive and procedural texts in a multimedia learning environment. Journal of the American Society for Information Science, 47(6), 437-448.

[48] Lee, D. Y., \& Shin, D.-H. (2011). Effects of spatial ability and richness of motion cue on learning in mechanically complex domain. Computers in Human Behavior, 27(5), 16651674.

[49] Lee, E. A.-L., \& Wong, K. W. (2014). Learning with desktop virtual reality: Low spatial ability learners are more positively affected. Computers \& Education, 79, 49-58.

[50] Lin, L., Atkinson, R. K., Savenye, W. C., \& Nelson, B. C. (2016). Effects of visual cues and self-explanation prompts: empirical evidence in a multimedia environment. Interactive Learning Environments, 24(4), 799-813.

[51] Lowe, R., \& Boucheix, J. (2007). Eye tracking as a basis for animation design. In Bi-annual meeting of the European Association of Research on Learning and Instruction, Budapest.

[52] Malone, S., \& Brünken, R. (2013). Assessment of driving expertise using multiple choice questions including static vs. animated presentation of driving scenarios. Accident Analysis \& Prevention, 51, 112-119.

[53] Mautone, P. D., \& Mayer, R. E. (2001). Signaling as a cognitive guide in multimedia learning. Journal of Educational Psychology, 93(2), 377.

[54] Mayer, R. E., \& Anderson, R. B. (1992). The instructive animation: Helping students build connections between words and pictures in multimedia learning. Journal of Educational Psychology, 84(4), 444.

[55] Mayer, R. E., \& Chandler, P. (2001). When learning is just a click away: Does simple user interaction foster deeper understanding of multimedia messages? Journal of Educational Psychology, 93(2), 390. 
[56] Mayer, R. E., DeLeeuw, K. E., \& Ayres, P. (2007). Creating retroactive and proactive interference in multimedia learning. Applied Cognitive Psychology, 21(6), 795-809.

[57] Mayer, R. E., Dow, G. T., \& Mayer, S. (2003). Multimedia learning in an interactive selfexplaining environment: What works in the design of agent-based microworlds? Journal of Educational Psychology, 95(4), 806.

[58] Mayer, R. E., \& Moreno, R. (1998). A splitattention effect in multimedia learning: Evidence for dual processing systems in working memory. Journal of Educational Psychology, 90(2), 312.

[59] Mayer, R. E., \& Sims, V. K. (1994). For whom is a picture worth a thousand words? Extensions of a dual-coding theory of multimedia learning. Journal of Educational Psychology, 86(3), 389.

[60] McEldoon, K. L., Durkin, K. L., \& RittleJohnson, B. (2013). Is self-explanation worth the time? A comparison to additional practice. British Journal of Educational Psychology, 83(4), 615-632.

[61] McElhaney, K. W., Chang, H.-Y., Chiu, J. L., \& Linn, M. C. (2015). Evidence for effective uses of dynamic visualisations in science curriculum materials. Studies in Science Education, 51(1), 49-85.

[62] Moreno, R. (2007). Optimising learning from animations by minimising cognitive load: Cognitive and affective consequences of signalling and segmentation methods. Applied Cognitive Psychology: The Official Journal of the Society for Applied Research in Memory and Cognition, 21(6), 765-781.

[63] Moreno, R. (2009). Learning from animated classroom exemplars: The case for guiding student tea che rs' observa tions with metacognitive prompts. Educational Research and Evaluation, 15(5), 487-501.

[64] Moreno, R., \& Mayer, R. E. (1999). Cognitive principles of multimedia learning: The role of Moreno, R., \& Mayer, R. E. (1999). Cognitive principles of multimedia learning: The role of modality and contiguity. Journal of Educational Psychology, 91(2), 358.modality and contiguity. Journal of Educational Psychology, 91(2), 358.

[65] Moreno, R., \& Mayer, R. E. (2002). Learning science in virtual reality multimedia environments: Role of methods and media. Journal of Educational Psychology, 94(3), 598.

[66] Moreno, R., Mayer, R. E., Spires, H. A., \& Lester, J. C. (2001). The case for social agency in computer-based teaching: Do students learn more deeply when they interact with animated pedagogical agents? Cognition and Instruction, 19(2), 177-213.

[67] Murphy, N., \& Messer, D. (2000). Differential benefits from scaffolding and children working alone. Educational Psychology, 20(1), 17-31.

[68] Narayanan, N. H., \& Hegarty, M. (2002). Multimedia design for communication of dynamic information. International Journal of Human-Computer Studies, 57(4), 279-315.

[69] O'Neil, H. F., Mayer, R. E., Herl, H. E., Niemi, C., Olin, K., \& Thurman, R. A. (2000). Instructional strategies for virtual aviation training environments. Aircrew Training and Assessment, 105-130.

[70] Ollerenshaw, A., Aidman, E., \& Kidd, G. (1997). Is an illustration always worth ten thousand words? Effects of prior knowledge, learning style and multimedia illustrations on text comprehension. International Journal of Instructional Media, 24(3), 227.

[71] Park, O., \& Gittelman, S. S. (1992). Selective use of animation and feedback in computerbased instruction. Educational Technology Research and Development, 40(4), 27-38.

[72] Park, S. I., Lee, G., \& Kim, M. (2009). Do students benefit equally from interactive computer simulations regardless of prior knowledge levels? Computers \& Education, 52(3), 649-655.

[73] Plass, J. L., Chun, D. M., Mayer, R. E., \& Leutner, D. (2003). Cognitive load in reading a foreign language text with multimedia aids and 
the influence of verbal and spatial abilities. Computers in Human Behavior, 19(2), 221243.

[74] Pratt, M. W., \& Savoy-Levine, K. M. (1998). Contingent tutoring of long-division skills in fourth and fifth graders: Experimental tests of some hypotheses about scaffolding. Journal of Applied Developmental Psychology, 19(2), 287-304.

[75] Rieber, L. P. (1990). Using computer animated graphics in science instruction with children. Journal of Educational Psychology, 82(1), 135.

[76] Rittle-Johnson, B. (2006). Promoting transfer: Effects of self-explanation and direct instruction. Child Development, 77(1), 1-15.

[77] Schneider, S., Beege, M., Nebel, S., \& Rey, G. D. (2018). A meta-analysis of how signaling affects learning with media. Educational Research Review, 23, 1-24.

[78] Schnotz, W., \& Rasch, T. (2005). Enabling, facilitating, and inhibiting effects of animations in multimedia learning: Why reduction of cognitive load can have negative results on learning. Educational Technology Research and Development, 53(3), 47.

[79] Sharma, P., \& Hannafin, M. J. (2007). Scaffolding in technology-enhanced learning en viro nmen ts. Int er ac tive Le a rnin $\mathrm{g} E \mathrm{n}$ v i r o n m e n t s, 15 ( 1 ), $27-46$. https://doi.org/10.1080/10494820600996972

[80] Sims, V. K., \& Hegarty, M. (1997). Mental animation in the visuospatial sketchpad:
Evidence from dual-task studies. Memory \& Cognition, 25(3), 321-332.

[81] Smit, N., van de Grift, W., de Bot, K., Jansen, E., de Pol, J., Volman, M., \& Beishuizen, J. (2017). A classroom observation tool for scaffolding reading comprehension. Educational Psychology Review, 22(3), 271-296.

[82] Spanjers, I. A. E., Wouters, P., Van Gog, T., \& Van Merrienboer, J. J. G. (2011). An expertise reversal effect of segmentation in learning from animated worked-out examples. Computers in Human Behavior, 27(1), 46-52.

[83] Stebner, F., Kühl, T., Höffler, T. N., Wirth, J., \& Ayres, P. (2017). The role of process information in narrations while learning with animations and static pictures. Computers \& Education, 104, 34-48.

[84] Steinke, M., Huk, T., \& Floto, C. (2003). Helping teachers developing computer animations for improving learning in science education. In Society for Information Technology \& Teacher Education International Conference (pp. 3022-3025).

[85] Tversky, B., Morrison, J. B., \& Betrancourt, M. (2002) . Animation: can it facilitate? International Journal of Human-Computer Studies, 57(4), 247-262. van Wely, M. (2014). The good, the bad and the ugly: meta-analyses. Oxford University Press.

[86] Xie, H., Wang, F., Zhou, Z., \& Wu, P. (2016). Cueing effect in multimedia learning: A metaanalysis. Acta Psychologica Sinica, 48(5), 540-555 